\title{
Statement of support for Professor Glenda Gray and the principle of academic freedom of speech
}

\begin{abstract}
As scientists, academics and policy experts, we are committed to being part of the complex policy response and debate on dealing with the epidemic of SARS-CoV-2 (the cause of COVID-19) in South Africa. We recognise that it is impossible to have perfected the response to the epidemic, but course correction should be rapid and not defensive. With that in mind, we condemn the specific threat made against Prof. Glenda Gray for expressing her opinion in public, which is totally out of step with the public pronouncements made by the President, welcoming criticism. We uphold the right to academic freedom of speech, and call on the South African government to engage openly with alternative views, and for all of us to urgently work towards constructive solutions regarding policy, in the interests of the country.
\end{abstract}

\section{Prof. Francois Venter}

Ezintsha, sub-division of Wits Reproductive Health and HIV Institute, University of the Witwatersrand, Johannesburg, South Africa fventer@wrhi.ac.za,venter.francois@gmail.com

Current signatures (alphabetical order), as of 16h00, Monday 25 May 2020. The list is now closed, although you can add your name at the bottom of the Daily Maverick site (https://www. dailymaverick.co.za/article/2020-05-25-250-senior-academicsissue-statement-to-support-prof-glenda-gray-and-the-principleof-academic-freedom/?tl_inbound $=1 \& \mathrm{tl}$ _groups [0] $=80895 \& \mathrm{tl}$ period_type $=3 \&$ utm_medium $=$ email\&utm_campaign $=$ Business $\% 20$ Maverick\%20 Monday\%2 $025 \% 20$ May\%2 $02020 \% 20$ - \%20 NinetyOne\&utm_content=Business\%20Maverick\%20Monday\%20 25\%20May\%202020\%20-\%20NinetyOne+CID_c60885d94179ffb 14 9d6d610c2f4435e\&utm_source $=$ TouchBasePro\&utm_term $=250 \% 20$ senior\%20academics\%20issue\%20statement\%20to\%20support $\% 20$ Prof $\% 20$ Glenda $\% 20$ Gray\%20and $\% 20$ the $\% 20$ Principle $\% 20$ of $\% 20$ Academic\%20Freedom)

Dr Fareed Abdullah, Director: Office of AIDS and TB Research, South African Medical Research Council

Prof. Sumaiya Adam, Obstetrics and Gynaecology, University of Pretoria

Dr Khatija Ahmed, CEO, Setshaba Research Centre

Prof. Kate Alexander, South African Research Chair in Social Change and Director: Centre for Social Change, University of Johannesburg

Prof. Cathi Albertyn, School of Law, University of the Witwatersrand Prof. Lucy Allais, Professor of Philosophy, University of the

Witwatersrand, Henry Allison Chair of the History of Philosophy, UCS Shafrudeen Amod, Clinical Pharmacist and Health Law, University of KwaZulu-Natal

Dr Chris Archer, CEO, South African Private Practitioners Forum (SAPPF)

Dr Cecile Baard, GP, aesthetic medicine, private practice, Pretoria Lee Baker, President and on behalf of the South African Society of Travel Medicine

Dr Scott Barker, Private practice, Cape Town

Prof. Karen I Barnes, Division of Clinical Pharmacology, University of Cape Town
Prof. Dan Barouch, William Bosworth Castle Professor of Medicine, Harvard Medical School, Ragon Institute of MGH, MIT and Harvard, Director of the Center for Virology and Vaccine Research; Beth Israel Deaconess Medical Center

Dr Peter Barron, School of Public Health, University of the Witwatersrand

Dr Michael Barrow, Orthopaedic surgeon, private practice Prof. Linda Basson, Department of Zoology and Entomology, University of the Free State

Dr Zaheer Bayat, Head of Internal Medicine, Head of Endocrinology, Diabetes and Metabolism, Helen Joseph Hospital and University of the Witwatersrand

Prof. Linda-Gail Bekker, Director, Desmond Tutu HIV Foundation, University of Cape Town

Dr Peter-John Berlyn, Paediatrician, Kimberley

Prof. Chris Beyrer, Desmond M Tutu Professor in Public Health and Human Rights, Johns Hopkins Bloomberg School of Public Health, Baltimore, MD, USA; and Past President, International AIDS Society, International Co-Chair for AIDS 2016 in Durban, South Africa Priya Bhana, Perinatal HIV Research Unit, University of the Witwatersrand

Prof. Haroon Bhorat, Development Policy Research Unit, University of Cape Town

Dr Geoffrey Bihl, Nephrologist, private practice, Western Cape Dr Duanne Blaauw, School of Public Health, University of the Witwatersrand

Dr John Black, Infectious diseases physician at Livingstone Hospital and University of Cape Town

Dr Michael Blackburn, Specialist anaesthesiologist, private practice, Johannesburg

Dr M Blaylock, Medical manager, Manguzi Hospital, KwaZulu-Natal Prof. Frikkie Booysen, School of Economics and Finance, University of the Witwatersrand

Dr Johan Botha, DermAfrica

Natalie Bracher, Hutchinson Centre Research Institute of South Africa

Prof. Keith Breckenridge, WISER, University of the Witwatersrand Dr David Brittain, Clinical haematologist, private practice,

Johannesburg

Prof. Adrian Brink, Head, Department of Medical Microbiology, University of Cape Town

Garth Brink, Family physician, Durban

Dr Sarahan Brophy, private GP, Sea Point, Cape Town

Dr Susan Buchbinder, Prof., Medicine and Epidemiology, UCSF,

Member, Executive Management Team, HIV Vaccine Trials Network (in USA)

Dr Suvarna Buldeo, Clinical pathologist, KwaZulu-Natal Prof. Catherine Burns, Associate Professor of Medical History; Adler Museum of Medicine; Faculty of Health Sciences, University of the Witwatersrand

Mr Hennie Butler, Department of Zoology and Entomology, University of the Free State

Prof. Lydia Cairncross, Department of Surgery, University of Cape Town 
Dr Robert-Ian Caldwell, Physician, Knysna

Dr Alistair D Calver, Internal Medicine, Tshepong Hospital,

Klerksdorp, and University of the Witwatersrand

Prof. Daniela Casale, School of Economics and Finance, University of the Witwatersrand

Prof. Sarah Charlton, School of Architecture and Planning, University of the Witwatersrand

Prof. Nithaya Chetty, Dean, Faculty of Science, University of the Witwatersrand

Prof. Sean Chetty, Executive Head, Department of Anaesthesiology and Critical Care, Stellenbosch University

Dr Frank Chidawanyika, Department of Zoology and Entomology, University of the Free State

Prof. Usuf Chikte, Emeritus Professor, Department of Global Health, Stellenbosch University

Dr Wezile Chitha, Assistant Dean: Strategic Affairs, Co-Director: Health Systems Enablement \& Innovation Unit, Faculty of Health Sciences, University of the Witwatersrand

Prof. T E Cloete, Deputy Vice-Chancellor: Research, Innovation and Postgraduate Studies, Stellenbosch University

Prof. Daryl Codron, Department of Zoology and Entomology, University of the Free State

Dr Jacqueline Codron, Centre for Environmental Management, University of the Free State

Dr Jenny Coetzee, Perinatal HIV Research Unit, University of the Witwatersrand

Prof. Jason Cohen, Deputy Dean, Faculty of Commerce, Law and Management, University of the Witwatersrand

Dr Francesca Conradie, Clinical HIV Research Unit, University of the Witwatersrand

Prof. Demitri Constantinou, Professor: Sports and Exercise Medicine and Director: Centre for Exercise Science and Sports Medicine,

University of the Witwatersrand

Emeritus Associate Prof. David Cooper, Sociology, University of Cape Town

Prof. Co-Pierre Georg, School of Economics, University of Cape Town Prof. Ashraf Coovadia, Chief Specialist and Head of Department of Paediatrics and Child Health, Rahima Moosa Mother and Child Hospital and University of the Witwatersrand

Prof. Larry Corey, Past President, Fred Hutchinson Research Center; and Principal Investigator of the HIV Vaccine Trials Network Prof. Mark Cotton, Department of Paediatrics and Child Health, Stellenbosch University

Prof. Keith Cowan, Director, Institute for Environmental

Biotechnology, Rhodes University

Prof. Vernon Coyne, Department of Molecular and Cell Biology,

University of Cape Town

Prof. Mary Crewe, Centre for the Study of AIDS, University of Pretoria Prof. Reza Daniels, School of Economics, University of Cape Town Dr Aslam Dasoo, Progressive Health Forum

Prof. Joel Dave, Head of Division of Endocrinology, University of Cape Town

Prof. Mary-Ann Davies, Director, Associate Professor and Public Health Medicine Specialist, Centre for Infectious Disease Epidemiology and Research, University of Cape Town

Halima Dawood, Head of Clinical Unit: Infectious Diseases, Grey's Hospital

Prof. Danie de Klerk, Assistant Dean, Faculty of Commerce, Law and Management, University of the Witwatersrand

Dr Albie de Frey, Senior Honorary Lecturer in Travel Medicine at the School of Public Health, University of the Witwatersrand
Prof. Wim de Villiers, Rector and Vice-Chancellor, Stellenbosch

University

Prof. Thea de Wet, Sr Director: Centre for Academic Technologies (CAT), University of Johannesburg

Dr J C de Witt, Paediatrician

Prof. Ames Dhai, Professor of Bioethics, University of the Witwatersrand

Dr Janan Dietrich, Perinatal HIV Research Unit, University of the Witwatersrand

Dr Rowan Dunkley, Paediatric consultant, Red Cross War Memorial Children's Hospital

Prof. Paul Dunne, School of Economics, University of Cape Town Dr Jenny Durandt, GP, family medicine tutor, University of Cape Town

Dr Rob Dyer, Cardiologist, Durban

Niles Eaton, HIV Vaccine Trials Network at the Fred Hutchinson Cancer Research Center

Andries Engelbrecht, HIV Vaccine Trials Network

Prof. David Everatt, Wits School of Government, University of the Witwatersrand

Dr Gail Faller, Paediatric rheumatologist. Wits Donald Gordon Medical Centre, Johannesburg

Prof. Emeritus Susan Fawcus, Senior Scholar, Department of Obstetrics and Gynaecology, University of Cape Town

Dr Hannetjie Ferreira, MDR/XDR TB Unit, North West Province

Dr Stephanie Fischer, Anaesthetist, Johannesburg

Dr Judith Flett, Anaesthesiologist, Pretoria

Prof. Pier Paolo Frassinelli, School of Communication, University of Johannesburg

Prof. John Gear, ex Head of Public Health, University of the

Witwatersrand

Prof. Tim Gebbie, Department of Statistical Sciences, University of Cape Town

Dr Daleen Geldenhuys (Kotze), Specialist physician/medical oncologist, private practice

Dr Huub Gelderblom, Physician, HIV Vaccine Trials Network, Seattle Prof. Jaya George, Head of Chemical Pathology, University of the Witwatersrand

Dr Rhodé Gerber, General practitioner, private practice, KwaZulu-

Natal

Prof. Nico C Gey van Pittius, Vice-Dean: Research and

Internationalisation and Professor in Molecular Biology, Dean's

Division, Faculty of Medicine and Health Sciences, Stellenbosch

University

Dr Elna Gibson, Paediatrician, Hermanus

Dr Janet Giddy, Family physician. Cape Town

Prof. Peter Gilbert, Principal Investigator of the Statistical Data

Management Center, HIV Vaccine Trials Network

Dr Katherine Gill, CRS Leader, Desmond Tutu HIV Foundation, University of Cape Town

Prof. Daryl Glaser, Political Studies, School of Social Sciences,

University of the Witwatersrand

Prof. Debbie Glencross, Department of Molecular Medicine and Haematology, University of the Witwatersrand

Prof. Gregg Gonsalves, Yale School of Public Health, New Haven, USA

Dr Dean Gopalan, President, Critical Care Society of South Africa

Dhevium Govender, HCRISA, HIV Vaccine Trials Network

Prof. Robin Green, Chairman, School of Medicine, University of Pretoria Dr Pamela Groenewald, Burden of Disease Research Unit, South

African Medical Research Council 
Dr Michelle J Groome, Senior clinical researcher and medical epidemiologist, Respiratory and Meningeal Pathogens Research Unit, University of the Witwatersrand

Prof. Adam Habib, Vice-Chancellor, University of the Witwatersrand Dr Scott M Hammer, Harold C Neu Professor of Infectious Diseases, Columbia University, Irving Medical Center; Member, Executive Management Team, HIV Vaccine Trials Network

Dr Lucia Hans, Clinical virologist, Molecular Medicine and Haematology, University of the Witwatersrand

Dr Sian Hartshorne, President, South African Society for Dermatological Surgery; and University of the Witwatersrand Dr Woltemade Hartman, Clinical psychologist and Executive Board Member of the International Society of Clinical Hypnosis

Prof. Mark Hatherill, Director, South African Tuberculosis Vaccine Initiative, University of Cape Town

Dr Yolandie Hayden, Private practice, Pretoria

Prof. Kim Hein, Emeritus Professor, University of the Witwatersrand Prof. Inga Hitzeroth, Deputy Director, Biopharming Research Unit, Department of Molecular and Cell Biology, University of Cape Town Dr Temlett Hockey, Paediatrician, Paarl

Dr Ronald Hockman, Anaesthesiologist, Gauteng

Prof. Nicola Illing, Department of Molecular and Cell Biology, University of Cape Town

Prof. Robert Ingle, Department of Molecular and Cell Biology, University of Cape Town

Prof. Charles Haddad, Department of Zoology and Entomology, University of the Free State

Prof. Shireen Hassim, WISER, University of the Witwatersrand Prof. W F Harris, Emeritus Professor, University of Johannesburg Dr Rebecca Hodes, AIDS and Society Research Unit, University of Cape Town

Dr Cara Hollander, Prime Hearing, University of the Witwatersrand Kathryn L Hopkins, Perinatal HIV Research Unit, Faculty of Health Sciences, University of the Witwatersrand

Prof. Mitchell Hughes, School of Business Sciences, University of the Witwatersrand

Prof. Jannie Hugo, Department of Family Medicine, University of Pretoria

Prof. Tracy Lynn Humby, School of Law, University of the Witwatersrand

Prof. Barry Jacobson, Head, Clinical Haematology, National Health Laboratory Service

Prof. Ian Jandrell, Dean, Faculty of Engineering and the Built Environment, University of the Witwatersrand

Prof. Jonathan Jansen, Stellenbosch University

Dr Candice Jansen van Rensburg, Department of Zoology and Entomology, University of the Free State

Dr Bhavna Jasmat, Paediatrician

Dr Zainub Jooma, Department of Anaesthesia, Charlotte Maxeke Johannesburg Academic Hospital and University of the Witwatersrand Prof. Stephen Jurisich, Head: School of Statistics and Actuarial Science, University of the Witwatersrand

Dr Eb Kader, Neuro and General Interventionalist, Department of Neurosurgery, University of Cape Town; and Faculty of Medicine, Stellenbosch University

Prof. Kathy Kahn, School of Public Health, University of the Witwatersrand

Prof. Bavesh Kana, Personal Professor, University of the Witwatersrand Dr Yatish Kara, Paediatrics, Chairman of the South African Private Practice Forum
Prof. Jonathan Klaaren, School of Law, University of the Witwatersrand

Prof. Hester C Klopper, Deputy Vice-Chancellor: Strategy and Internationalisation, Global Health, FMHS, Stellenbosch University Prof. Uma Kollamparambil, Head, School of Economics and Finance, University of the Witwatersrand

Emeritus Prof. Beverley Kramer, School of Anatomical Sciences, University of the Witwatersrand

Prof. Anna Kramvis, Director, Hepatitis Virus Diversity Research Unit, Department of Internal Medicine, University of the Witwatersrand Dr Nico Mostert Kritzinger, General practitioner, Klerksdorp Prof. Mariana Kruger, Executive Head, Department of Paediatrics and Child Health, Stellenbosch University

Prof. James Kublin, Executive Director of the HIV Vaccine Trials Network; Medical Director of the Malaria Clinical Trials Center at Seattle Biomed; Professor of Global Health at the University of Washington

Dr Richard Kyte, Orthopaedic surgeon, Wits Donald Gordon Medical Centre

Dr Anita Lai, Private practice, sessional rheumatologist at Helen Joseph Academic Hospital, University of the Witwatersrand

Dr Erica Lazarus, Perinatal HIV Research Unit, University of the Witwatersrand

Prof. Anthony Leaman, School of Economics, University of Cape Town

Prof. Murray Leibbrandt, SALDRU, University of Cape Town

Prof. Johann Lemmer, President, Council for Sexual Health

Professions, South Africa - on behalf of $>20$ colleagues at CSHP

Engelbert le Roux, HCRISA

Prof. Naomi Levitt, Emeritus Professor of Endocrinology, University of Cape Town

Prof. Anthony Leysens, Dean, Faculty of Arts and Social Sciences, Stellenbosch University

Dr Carien Lion-Cachet, Family physician, joint appointee, J B Marks Sub-District DoH and Department of Family Medicine, University of the Witwatersrand

Prof. Theresa Lorenzo, Disability Studies and Occupational Therapy, Faculty of Health Sciences, University of Cape Town

Dr Susan Louw, Department of Molecular Medicine and Haematology, University of the Witwatersrand

Prof. Gary Maartens, Head of Clinical Pharmacology, University of Cape Town

Prof. Shabir Madhi, Professor of Vaccinology and Director of the MRC Respiratory and Meningeal Pathogens Research Unit, University of the Witwatersrand

Dr Gloria Maimela, Director Health Programmes, Wits Reproductive Health and HIV Institute, University of the Witwatersrand Dr Mookho Malahleha, Deputy CEO, Setshaba Research Centre Prof. Helder Marques, Faculty of Science, University of the Witwatersrand

Dr Troy Martin, Chief of Staff, Fred Hutchinson Cancer Research Center, HIV Vaccine Trials Network (in USA)

Ms Velashka Martin, Faculty of Commerce, Law and Management, University of the Witwatersrand

Dr Neil Martinson, Perinatal HIV Research Unit, University of the Witwatersrand

Dr Moeketsi Mathe, Private practice; lecturer, University of the Witwatersrand 
Dr Catherine Mathews, South African Medical Research Council; and School of Public Health and Family Medicine, University of Cape Town

Prof. Richard Matzopoulos, Chief Specialist and Co-Director: Burden of Disease Research Unit, South African Medical Research Council

Fatima Mayat, Perinatal HIV Research Unit

Dr Elizabeth Mayne, Department of Molecular Medicine and Haematology, University of the Witwatersrand

Prof. Marc Mendelson, Head, Division of Infectious Diseases and HIV Medicine, University of Cape Town

Prof. Colin Menezes, Academic Head, Department of Internal Medicine, School of Clinical Medicine, Faculty of Health Sciences, University of the Witwatersrand

Prof. Thaddeus Metz, Distinguished Professor, University of Johannesburg

Prof. Gesine Meyer-Rath, HERO, University of the Witwatersrand Prof. Adam Mahomed, Head of Internal Medicine, Charlotte Maxeke Johannesburg Academic Hospital and University of the Witwatersrand Dr Marinda McDonald, Private practice, Johannesburg

Prof. Juliana M McElrath, Professor and Director of the Vaccine and Infectious Disease Division, Senior Vice-President of the Fred Hutchinson Cancer Research Center, Member, Executive Management Team, HIV Vaccine Trials Network

Dr Kirsty McHarry, Private practice, Knysna

Prof. James McIntyre, School of Public Health and Family Medicine, University of Cape Town

Dr Kate Mclachlan, General practitioner, Somerset West

Dr Gary McMichael, Specialist physician/medical oncologist, private practice, Flora

Dr Ruchika Meel, Consultant cardiologist and Post-Doctoral Carnegie Fellow, Cardiology, Chris Hani Baragwanath Hospital and University of the Witwatersrand

Prof. Shaheen Mehtar, Emeritus Professor, Stellenbosch University Minja Milovanovic, Perinatal HIV Research Unit, University of the Witwatersrand

Prof. Tessa Minter, College of Accountancy, University of Cape Town Prof. Duncan Mitchell, Emeritus Professor of Physiology, Faculty of Health Sciences, University of the Witwatersrand

Dr Kirsten Mitchell, Specialist anaesthetist, private practice

Prof. Valerie Mizrahi, Institute of Infectious Disease and Molecular Medicine, University of Cape Town

Dr Bhadrashil Modi, Lecturer, Department of Family Medicine and Primary Care, University of the Witwatersrand

Dr Lerato Mohapi, Perinatal HIV Research Unit, University of the Witwatersrand

Prof. Rafique Moosa, Executive Head, Department of Medicine, Stellenbosch University

Prof. Yunus Moosa, Chief Specialist and Head, Department of Infectious Diseases, University of KwaZulu-Natal

Dr Reno Morar, Chief Operating Officer, University of Cape Town Dr Saber Mosam, Tshepong Hospital, Internal Medicine; Lecturer, School of Clinical Medicine, University of the Witwatersrand Dr Morne Mostert, Director: Institute for Futures Research, Stellenbosch University

Prof. Robert Morrell, Office of the Vice-Chancellor Department, University of Cape Town

Prof. Mike Morris, Economics, University of Cape Town Dr Harry Moultrie, Medical epidemiologist, Centre for Tuberculosis, National Institute for Communicable Diseases
Dr Deane Murfin, Anaesthetist, Donald Gordon Medical Centre,

University of the Witwatersrand

Dr Firdaus Nabeemeeah, Perinatal HIV Research Unit, University of the Witwatersrand

Dr Tracey Naledi, Public health specialist, University of Cape Town Anusha Nana, Perinatal HIV Research Unit, University of the Witwatersrand

Warren Nebe, RDT, Founder Drama for Life, Department of Applied Arts, Arts Therapies and Arts Research, University of the Witwatersrand

Prof. Nicoli Nattrass, School of Economics, University of Cape Town Dr Jeremy Nel, Department of Clinical Medicine, Faculty of Health Sciences, University of the Witwatersrand

Dr Busisiwe Nkala-Dlamini, School of Human and Community Development, University of the Witwatersrand

Dr Debbie Norval, President, Aesthetic and Anti-Aging Society of South Africa

Dr Adam Nosworthy, Medical oncologist, Wits Donald Gordon Medical Centre

Prof. Ntobeko Ntusi, Head of Medicine, University of Cape Town

Dr Jackline Odhiambo, HIV Vaccine Trials Network

Dr Regina Osih, Senior technical expert, Aurum Institute

Prof. Ruksana Osman, DVC Academic, University of the

Witwatersrand

Prof. Kennedy Otwombe, Perinatal HIV Research Unit and School of Public Health, University of the Witwatersrand

Prof. Vishnu Padayachee, School of Economics and Finance, University of the Witwatersrand

Prof. Robin Palmer, Director of Clinical Legal Studies, School of Law, University of Canterbury, Christchurch, New Zealand

Dr Ravindre Panchia, Perinatal HIV Research Unit, University of the Witwatersrand

Prof. Maria Pappas, Assistant Dean of Research and Postgraduate Support, Faculty of Health Sciences, University of the Witwatersrand Prof. Charles Parry, Director: Alcohol, Tobacco and Other Drug Research Unit, South African Medical Research Council Prof. Jon Patricios, Sport and exercise medicine physician; Associate Professor, Wits Institute for Sport and Health (WISH), Faculty of Health Sciences, University of the Witwatersrand

Dr Frank B Persson, Clinical radiation oncologist, Vereeniging Prof. Craig Peter, Department of Botany, Rhodes University Debra Peters, Perinatal HIV Research Unit, University of the Witwatersrand

Prof. Audrey Pettifor, Department of Epidemiology, University of

North Carolina

Dr Beth Pheiffer, Gynaecologist, retired

Prof. Devan Pillay, Sociology Department, University of the Witwatersrand

Prof. Barney Pityana, Emeritus Professor, University of South Africa Dr Deidré Pretorius, Lecturer, Department of Family Medicine, University of the Witwatersrand Prof. Sharon Prince, Head, Department of Human Biology, Faculty of Health Sciences, University of Cape Town Prof. Juliet Pulliam, Director, South African DSI-NRF Centre of Excellence in Epidemiological Modelling and Analysis (SACEMA), Stellenbosch University Shelly Ramirez, HIV Vaccine Trials Network Yvette Raphael, Advocacy for Prevention of HIV and AIDS 
Dr Nika Raphaely, Public health medicine specialist, Charlotte Maxeke Johannesburg Academic Hospital and Department of Community Health, School of Public Health, University of the Witwatersrand

Prof. Peter Raubenheimer, Department of Medicine, University of Cape Town

Prof. Robert Reid, HoS Mechanical, Industrial and Aeronautical Engineering, University of the Witwatersrand

Prof. S J Reid, Glaxo-Wellcome Chair of Primary Health Care, Primary Health Care Directorate, University of Cape Town Dr Haroun Rhemtula, Head of Clinical Unit and Head of Obstetrics, Department of Obstetrics and Gynaecology, Charlotte Maxeke Johannesburg Academic Hospital and University of the Witwatersrand

Prof. Chrissie Rey, School of Molecular and Cell Biology, University of the Witwatersrand

Prof. Guy Richards, Emeritus Professor, University of the Witwatersrand

Dr Tyrone Richards, Emergency Medicine, Life Flora Hospital Dr Marlise Richter, African Centre for Migration and Society, University of the Witwatersrand

Dr Marina Rifkin, MHS, Epidemiologist, University of California San Francisco

Ela Romanowska, RTTP, Director: Innovation Support, Wits Commercial Enterprise

Dr Michelle Robinson, Medical officer, primary care, Johannesburg

Prof. David Root, HoS Construction Economics and Management, University of the Witwatersrand

Bill Rosenberg, BSc (Civ Eng)

Emeritus Prof. Bernd Rosenkranz, Faculty of Medicine and Health Sciences, Stellenbosch University

Prof. Jannie Rossouw, Wits Business School, University of the Witwatersrand

Prof. Paul Ruff, Head of Medical Oncology, Faculty of Health Sciences, University of the Witwatersrand

Prof. Pragna Rugunanan, Professor and Head of Department,

Department of Sociology, University of Johannesburg

Prof. Edward Rybicki, Biopharming Research Unit, Department of

Molecular and Cell Biology, University of Cape Town

Prof. Haroon Saloojee, Department of Paediatrics, University of the Witwatersrand

Prof. Vishwas Satgar, Department of International Relations,

University of the Witwatersrand

Prof. Gabriella Scarlatti, Head of research, Viral Evolution and Transmission Unit, IRCCS San Raffaele Scientific Institute, Milan, Italy; and professor at the Microbiology and Tumorbiology Center, Karolinska Institutet, Stockholm, Sweden

Dr Evan Shoul, Infectious diseases specialist, Milpark Hospital

Prof. M Schoeman, Head: Departmment of Political Sciences, Faculty of Humanities, University of Pretoria

Dr Ingrid Schoeman, Operational Manager, TB Proof

Prof. Lesley Scott, Department of Molecular Medicine and

Haematology, University of the Witwatersrand

Prof. Soraya Seedat, Executive Head, Department of Psychiatry,

Stellenbosch University

Prof. Jeremy Seekings, Centre for Social Science, University of Cape Town Dr Kate Shearer, Johns Hopkins University

Prof. Gayle Sherman, Empilweni Services and Research Unit, University of the Witwatersrand

Mr Fana Sibanyoni, Chief Operations Officer, University of the Witwatersrand
Dr Nandi Siegfried, Independent public health medicine specialist and Chief Specialist Scientist, Medical Research Council Dr Elvira Singh, School of Public Health, University of the Witwatersrand

Dr Helen Sommerville, Family physician, private practice, HIV practitioner

Prof. Martin Smith, School of Clinical Medicine, Faculty of Health Sciences, University of the Witwatersrand

Prof. Johan Smith, Department of Paediatrics and Child Health, Stellenbosch University

Dr Jonathan Smith, President: Dermatology Society of South Africa Dr Julian Smith, Paediatrician, Pretoria

Dr Geetesh Solanki, Senior Specialist Scientist, Health Systems Research Unit, South African Medical Research Council

Dr Simiso Sokhela, Ezintsha, Faculty of Health Sciences, University of the Witwatersrand

Prof. Kathy Sole, Department of Materials Science and Metallurgical Engineering, University of Pretoria

Prof. Mark Sonderup, Division of Hepatology, University of Cape Town

Prof. Antony Stacey, President: Academic Staff Association of Wits University (ASAWU), University of the Witwatersrand

Maria Stacey, Director, Equal International

Dr D M Stander, GP, Colesberg

Dr Kim Steegen, Department of Molecular Medicine and

Haematology, University of the Witwatersrand

Dr Simon Strachan, Paediatrician

Prof. Garth Stevens, Dean, Faculty of Humanities, University of the Witwatersrand

Prof. Wendy Stevens, Professor and Head, Department of Molecular Medicine and Haematology, University of the Witwatersrand

Dr S A Strachan, Paediatrician, Johannesburg

Prof. Leslie Swartz, Professor of Psychology, Stellenbosch University

Azwi Takalani, Regional Medical Liaison, Hutchinson Centre Research Institute of South Africa

Dr Fazleh Taleb, Neurosurgeon, private practice

Prof. Jantjie Taljaard, Head, Division of Infectious Diseases,

Stellenbosch University

Dr Mvuyiso Talatala, South African Society of Psychiatrists; and

Department of Psychiatry, University of the Witwatersrand,

Johannesburg

Dr Jill te Water Naudé, GP, Paarl

India Tindale, HIV Vaccine Trials Network

Prof. Steven Tollman, School of Public Health, University of the

Witwatersrand

Prof. Georgia Tomaras, Professor of Surgery, Immunology and

Molecular Genetics and Microbiology at Duke University; Director of Research for the Duke Human Vaccine Institute; Associate Director for the HIV Vaccine Trials Network Laboratory Center

Prof. Keyan Tomaselli, Faculty of Humanities, University of Johannesburg

Prof. Mark Tomlinson, Institute for Life Course Health Research, Department of Global Health, Faculty of Medicine and Health

Sciences, Stellenbosch University

Dr Michele Torlutter, Family physician, University of the

Witwatersrand

Prof. Estelle Trengove, School of Electrical and Information

Engineering, University of the Witwatersrand

Dr Richard Tuft, Executive Director, Radiological Society of South Africa Dr Astrid Turner, Specialist, Public Health Medicine, Faculty of Health Sciences, University of Pretoria 
Prof. Tina Uys, Department of Sociology, University of Johannesburg Prof. Imraan Valodia, Dean, Faculty of Commerce, Law and Management, University of the Witwatersrand

Prof. Liesl van As, Department of Zoology and Entomology, University of the Free State

Prof. John van den Berg, Department of Mathematics and Applied Mathematics, University of Pretoria

Prof. Alex van den Heever, Chair in the field of Social Security at the Wits School of Governance

Prof. Tess van der Merwe, Centres of Excellence for Metabolic Medicine and Surgery of South Africa, University of Pretoria

Dr Annemie van der Straeten, Private practice

Prof. C H van Heerden, Research Professor, Tshwane University of

Technology

Dr Nienke van Schaïk, Independent medical practitioner

Prof. Ebrahim Variava, Department of Internal Medicine, University of the Witwatersrand

Prof. Jo Vearey, African Centre for Migration and Society, University of the Witwatersrand

Prof. Martin Veller, Dean, Faculty of Health Sciences, University of the Witwatersrand

Prof. Zeblon Vilakazi, DVC Research, University of the Witwatersrand Dr Avy Violari, Perinatal HIV Research Unit, University of the Witwatersrand

Dr Heinrich Cyril Volmink, Public health medicine specialist Prof. Jimmy Volmink, Dean, Faculty of Health Sciences,

Stellenbosch University

Dr Arne von Delft, School of Public Health and Family Medicine,

University of Cape Town; and TB Proof co-founder

Dr Dalene von Delft, TB Proof co-founder and board member

Dr Tascha Vos, Centre for Environmental Management, University of the Free State
Prof. Gerhard Walzl, Executive Head, Biomedical Sciences, Stellenbosch University

Prof. Sean Wasserman, Infectious Diseases, Groote Schuur Hospital and University of Cape Town

Prof. Nicola Wearne, Division of Nephrology, University of Cape Town

Prof. Edward Webster, Southern Centre for Inequality Studies, University of the Witwatersrand

Prof. Alan Whiteside, OBE, Chair of Global Health Policy, BSIA, Waterloo, Canada; and Professor Emeritus, University of KwaZuluNatal

Prof. Michelle Williams, Department of Sociology, University of the Witwatersrand

Prof. Anna-Lise Williamson, Biopharming Research Unit, Department of Molecular and Cell Biology, University of Cape Town

Dr Jonathan Witt, Department of Anaesthesia, University of the Witwatersrand

Prof. M Wong, Academic Head: Pulmonology, School of Clinical Medicine, University of the Witwatersrand

Prof. Robin Wood, Director, Desmond Tutu HIV Centre, University of Cape Town

Dr Adrienne Wulfsohn, Emergency and Disaster Medicine, KwaZulu-

Natal

Ntando Yola, Advocacy for Prevention of HIV and AIDS

Dr Martin Young, Private practice

Dr Dayle Zieff, Groote Schuur HIV Clinical Services

S Afr Med J 2020;110(7):555-560. https://doi.org/10.7196/SAMJ.2020.v110i7.14964 